\title{
Falemos sobre o lixo: 0 trabalho da atriz que emerge do que está
fora de lugar
} We talk about the garbage: the work of the attracter that emerges from what is out of place

Stefanie Liz Polidoro ${ }^{1}$ 


\section{Resumo}

Neste artigo pretendo apresentar uma das questões que venho trabalhando em minha pesquisa de doutorado referente à investigação de práticas cênicas feministas, relacionada à produção de lixos e descartes (concretos, como resíduos alimentares; metafóricos, como a lapidação do vocabulário), e à possibilidade de criação a partir deste material. Como aporte teórico principal optei pela antropóloga Mary Douglas, e sua obra Pureza e Perigo: ensaio sobre a noção de poluição e tabu (1966), na qual discute a questão do descarte como algo que está fora de alguma ordem estabelecida. Para construir tal discussão, trago para dialogar comigo a personagem Ternurinha, uma mulher em situação de rua, criada no ano de 2009 durante minha graduação em Teatro na UFRGS, e que me acompanha ainda hoje.

Palavras-chave: Lixo; descarte; teatro feminista; escrita performativa

\section{Abstract}

In this article I intend to present one of the questions that I have been working on in my doctoral research concerning the investigation of feminist theather practices, related to the production of trash and discards (concrete, food waste, metaphorical, like stoning of vocabulary), and the possibility of creation from this material. As a main theoretical contribution I opted for the anthropologist Mary Douglas, and her work Purity and Danger: Essay on the Notion of Pollution and Taboo (1966), in which she discusses the issue of discarding as something outside of some established order. In order to construct such a discussion, I bring the character Ternurinha, a street woman, created in 2009 during my first degree in Theater at UFRGS, and who is still with me today.

Keywords: Garbage; discard; feminist theater; performative writing 
A criação do lixo é resultado de uma separação - o desejável do indesejável, o valioso do sem valor e, na verdade, o digno ou cultural do ordinário ou sem significado. (Scanlan apud Rial, 2016, p.20)

Meu nome é Stefanie Liz Polidoro, mas prefiro que tu te refiras a mim como Tefa - apelido que ganhei de minha mãe aos 4 meses de vida, e que carrego com muito carinho até hoje. Estou aqui para falar um pouco da pesquisa de doutorado que venho desenvolvendo no Programa de Pós-Graduação em Teatro da UDESC, com orientação da profa. Dra. Maria Brígida de Miranda, referente às estratégias que utilizo para pensar um possível fazer teatral feminista...ou um teatro feminista com o qual me identifico. Para este artigo proponho refletir sobre algumas questões que fazem parte destas minhas investigações e que estão relacionadas ao lixo (concreto e metafórico): como ele é produzido? Quais são suas atribuições? O que nosso lixo fala de nós? O lixo, matéria que carrega lembranças e ajuda a construir memórias, pode servir como matéria-prima para criação cênica? Estas são perguntas que Ternurinha lança para mim cotidianamente, e que fazem pensar sobre formas de consumo, maneiras de viver em sociedade, e também de produzir teatro... (Sinto cheiro de palheiro. Uma voz rouca e anasalada invade o espaço. É Ternurinha.)
$\mathrm{VOZ}-\mathrm{Oh}, \mathrm{tu} !$
TEFA- Eu?
VOZ - Sim, tu! Vem aqui!
TEFA - (Aproximo-me) Quê foi?
VOZ - Tu esqueceu de me apresentá. Tu falô meu nome mah não explicô qual Ternurinha que é...Pessoal pode pensá que tu tá falando da otra Ternurinha... aquela das gadeia loira, de bota branca até o joêio....amiga do rei. Não a Xuxa... ah otra...a que canta pro juiz pará o casamento...como que é o nome dela...a Wanderléa!!!!!!!!!!...Diz que ela também tem nome de Ternurinha, né...
TEFA - Desculpa, Ternurinha! Tu tens razão! O pessoal precisa te conhecer para ter melhor compreensão do que estou falando. Fica aqui ao meu lado para me ajudar.

Os primeiros rabiscos de Ternurinha surgiram no ano de 2009, durante minha graduação em Teatro na Universidade Federal do Rio Grande do Sul (UFRGS), precisamente na disciplina intitulada Composição de Personagem II, ministrada pelo professor Francisco de Assis Almeida Júnior. O enfoque daquele semestre era comicidade, e o grupo do qual eu fazia parte optou por trabalhar a partir das noções de bufonaria de Jacques Lecoq ${ }^{2}$. Daquele período tenho poucos registros: celulares com câmeras embutidas ainda não eram tão populares, e o arquivamento de materiais era feito em CDs e pen drives - que neste caso sucumbiram com o passar dos anos. Recordo de criar Ternurinha como uma mulher em situação de rua, que andava pelas calçadas do centro de Porto Alegre coberta por muitas roupas, tinha o olho esquerdo purulento e tapado com um lenço, cabelo bagunçado e sujo, dentes estragados, com seios grandes e uma faixa presidencial atravessada no peito.

\footnotetext{
${ }^{2}$ Ator e pesquisador teatral francês (1921 - 1999), fundador da escola francesa L'École Internationale de Théâtre Jacques Lecoq, conhecido por trabalhar máscaras (bufão e clown) e estilos teatrais (melodrama e tragédia)
} 
TERNURINHA - Eu tenho uma foto daquela época aqui na minha sacolinha. De repente é bom só pro pessoal vê como que eu era, né...como que eu fazia pra existí. Pera aí...

(Ternurinha procura o material que está dentro da sacola de plástico. A sacola está carregada de objetos aleatórios: garrafas de plástico, fitas cassete, panfletos de campanha política, uma boneca suja e sem perna, uma maçã já mordida e amarelada, uma cebola, algumas bitucas de cigarro, um saco de bolachas doces, alguns papelões, alguns livros manchados de umidade, entre tantas outras coisas que daqui não consigo enxergar. Objetivando encontrar a fotografia ela esvaziou sua sacola, deixando seu entorno aparentemente poluído e desorganizado, enquanto em sua sacola ficava apenas o material que precisava.)

TERNURINHA - Deu, tá aqui a foto.

TEFA - E essa sujeira toda que tu deixaste?

TERNURINHA - Quê sujêra? Essa são minhas coisa, não são sujêra. Eu vô recoiê tudo de volta enquanto que tu mostra os retrato pro pessoal.

TEFA - São tuas coisas? Mas tu vais comer esta maçã ainda?

TERNURINHA - Claro. Quando que me dá uma fome danada eu taco-lhe uma mordida. Iiih, essa maçã vai longe.

TEFA- E esses panfletos?

TERNURINHA - Uso pra limpá a bunda quando que mijo ou cago por aí. Banhêro público funciona só das $6 \mathrm{~h}$ da matina até umas $10 \mathrm{~h}$ da noite, e nem sempre tem papel, né?

TEFA - E a cebola?

TERNURINHA - Vai que me aparece um carretero pra botá ela...

TEFA - E as fitas cassete?

TERNURINHA - Tem um pessoal que faz um chá meio loco com elas...aí eu tiro uns pila vendendo, né.

TEFA - Tá, recolhe direitinho aí enquanto eu continuo conversando com o pessoal.

(Ternurinha começa a recolher seu material, mas fica resmungando baixinho coisas que não entendo)

Em princípio, Ternurinha era apenas resultado de um exercício de aula, realizado dentro da sala de ensaio, pensada e criada a partir da forma, da vontade de seguir os ditos de Lecoq, e de tatear o universo da bufonaria enquanto estilo de atuação. Não existia ainda a vontade, ou a consciência, de deixar-me aberta para o que Ternurinha pudesse me dizer. Naquele momento existia uma hierarquia muito bem estabelecida: eu a construía. Segue a foto de Ternurinha no ano de 2009: 


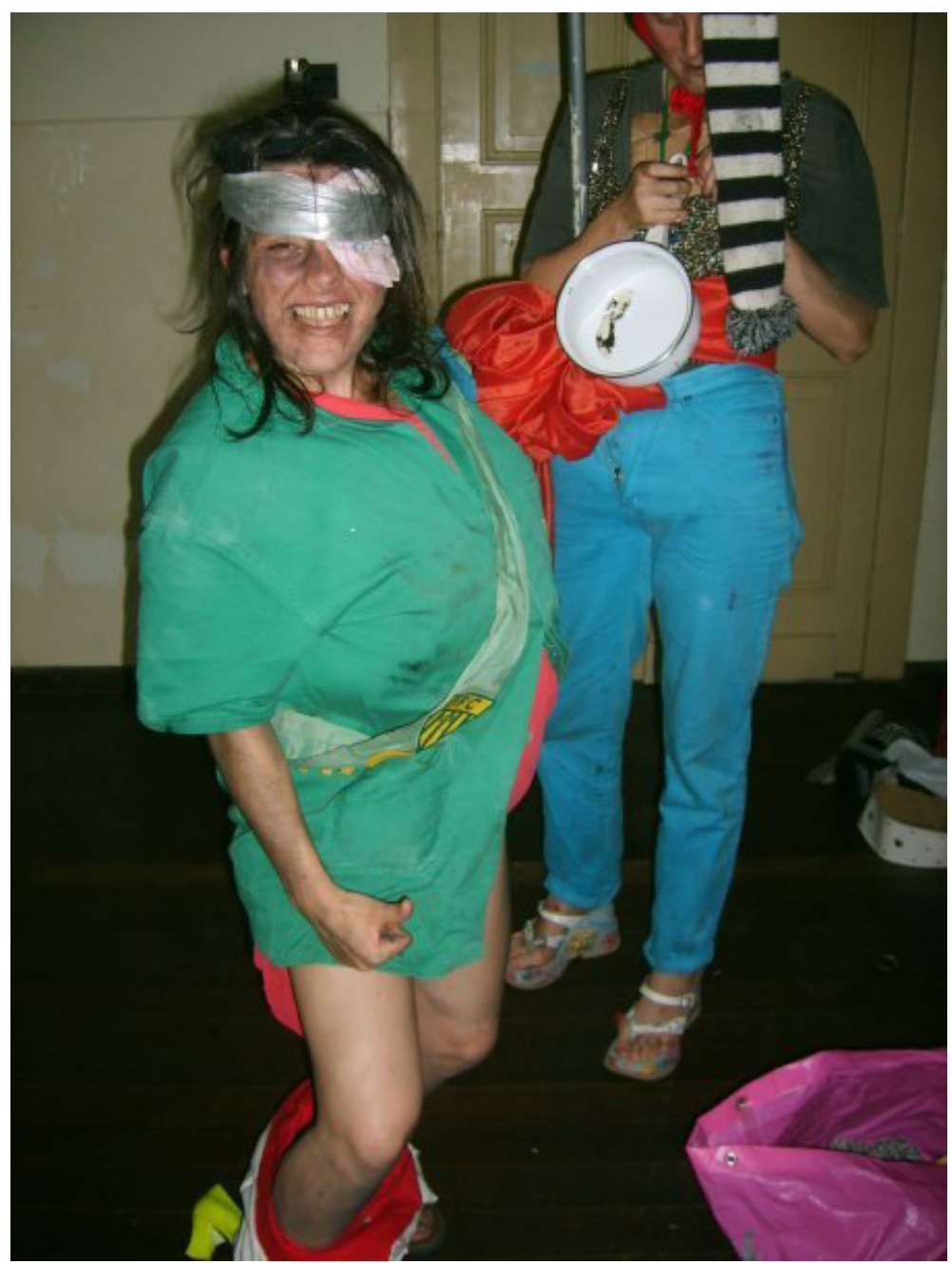

Figura 1 - Atriz Tefa Polidoro como Ternurinha Porto Alegre/RS - 2009

Arquivo pessoal de Tefa Polidoro.

Com o passar dos anos minha perspectiva em relação a ela foi se modificando, e isso se deve às vivências nas ruas às quais fui submetida por ela depois que a disciplina terminou. O que antes era forma, agora também começa a ganhar recheios com histórias...minhas histórias...memórias pessoais que levo à Ternurinha para que ela avalie...sugira...corrija...e me devolva... Ela acabou se tornando meu refúgio, onde adentro para me (re)construir, para depois colocar-me de volta ao mundo...e seguir...e voltar...e sair...e assim com ela caminhar. Hoje ela também me constrói...e vamos nos (re)aproveitando uma da outra.

TERNURINHA - É...eu ajudo ela faz um tempo já. Ela sempre foi das bailarina de ponta de pé, de ninfa, de jeito de falá todo certo, cheia de regra e não-me-toque, de não comê isso, não fazê aquilo, muito controladora de tudo. Era tanto controle dela cum ela mesma que a guria paralisô...um dia se trancafiô dentro de casa e nem saí pra rua mais ela conseguia. Aí eu apareci pra ajudá ela. Antes de tirá ela de casa, peguei ela pela mão e descemo até o porão da cabeça dela...

Tava tudo escuro...

com chêro de mofo...

Cheio de tranquêra...

Fazia tempo que ela não passava por lá.

Os lixo dela tudo empilhado debaxo da escada... 
Escondido.

Eu que ajudei a organizá tudo.

Pegamo o lixo e começamo a oiá coisa por coisa, e pensá em como tudo aquilo tinha saído dela...e não adiantava ela escondê aquilo tudo, ela tinha era que aceitá como dela, porque quando ela dá a descarga, por mais que a merda some da frente dela, não desfaz o fato de que foi ela quem cagô.

(Ternurinha larga suas sacolas no chão, e deita de lado, apoiando sua cabeça nelas. Ficamos por alguns segundos paradas...apenas nos olhando...)

TERNURINHA - Vai.

TEFA - Vai? Como assim? Onde?

TERNURINHA - Continua falando aí das tuas coisa...Já falei demais e tu nem tá me pagando nada.

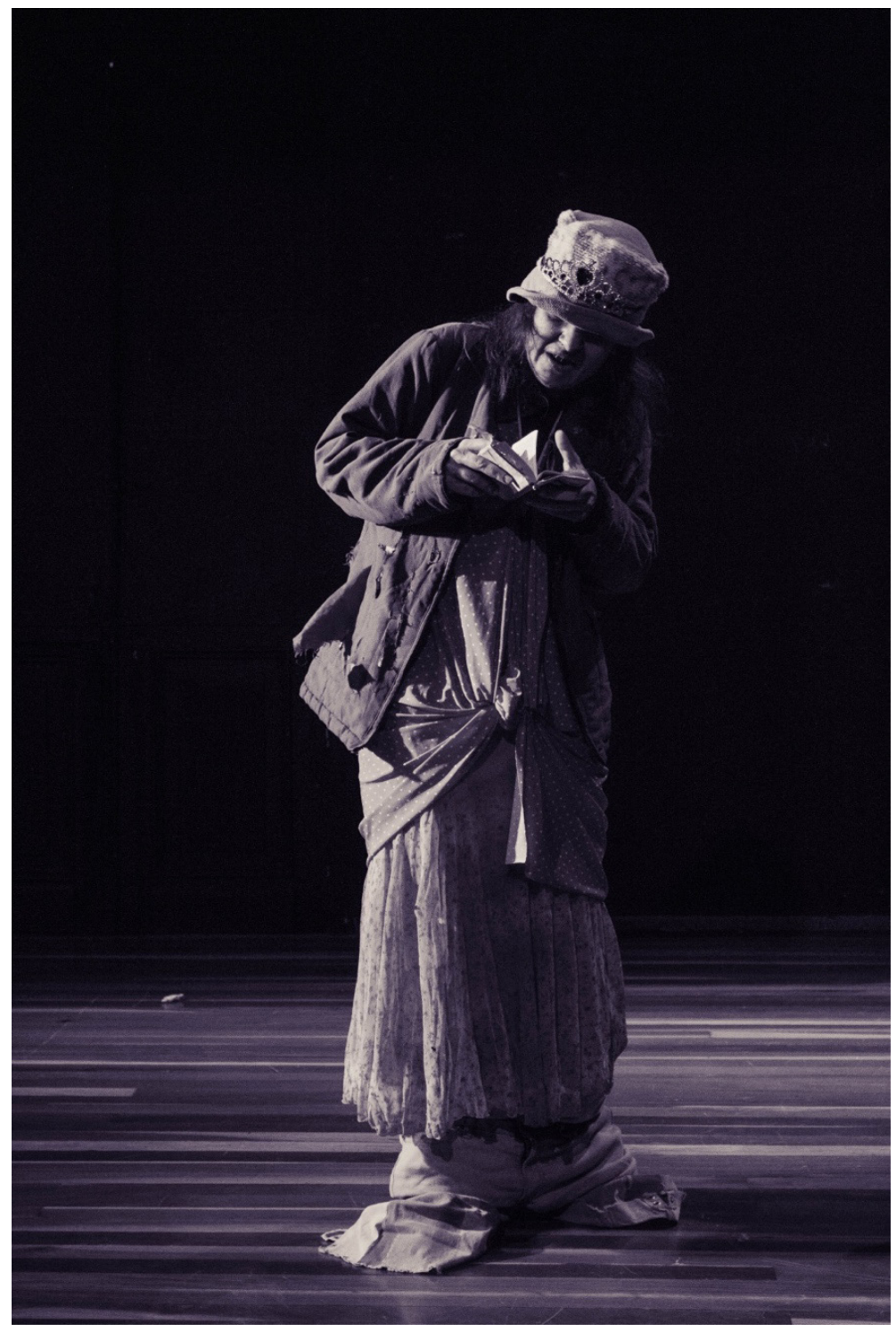

Figura 2 - Atriz Tefa Polidoro como Ternurinha. Porto Alegre/RS - 2018

Foto: Victória Sanguiné.

Ternurinha, conforme ela mesma disse há pouco, ajudou a me fazer sair de casa novamente. No ano de 2016 tive o que a psicologia e a psiquiatria chamam de TAG (Transtorno de Ansiedade Generalizada), cujos alguns sintomas, dentre tantos, são: 
medo de sair de casa, medo de estar em público, ansiedade pela falta de controle do futuro, e que se manifestam junto de vertigens, suadores, palpitações cardíacas, vontade de chorar, insônia, falta de fome, enjoos.... É um emaranhado de sensações que parecem fazer o peito explodir. Certo dia, numa das minhas consultas com a psicóloga Katia Viana Gazzola, comentei que às vezes em que eu saía como Ternurinha para a rua os sintomas sumiam. Era como se meu transtorno de ansiedade desaparecesse. Kátia sugeriu para que Ternurinha gravasse um vídeo falando sobre o que ela pensava a respeito de Tefa. Segue a transcrição das palavras de Ternurinha:

TERNURINHA - A Tefa é muito legal. Sempre que ela me encontra na rua ela conversa cum eu...toma cachaça comigo na calçada...paga pastel. Ela me trata bem...mah nunca me convidô pra entrá na casa dela, pra conhecê a família e tal. Ela veve falando de democracia e tal, mah tem um barrera capetalista bem clara dividindo nóis. Ela é minha amiga no público, mah quando é pra levá pro privado aí já vem lógica da demarcação de terra.

Foi a partir desta fala que comecei a prestar atenção em minhas próprias contradições, e nas contradições dos grupos dos quais faço parte. Ternurinha foi quem me mostrou a porta da autocrítica e colocou-me frente a frente com meus lixos, meus descartes. A aceitação dos defeitos era a primeira etapa para minha reformulação de sujeita. Aproximar-me deles era necessário para que eu conseguisse me reciclar, e este foi o caminho que optei para a cura do transtorno de ansiedade: perguntar a opinião de Ternurinha sobre tudo o que eu pensava, sentia ou fazia.

TERNURINHA - Teve um dia que a Tefa voltô a pegá avião, porque ela tinha dexado de andá de avião, né. Aí ela tava embarcada já, quase desistindo quando que ele tava quase decolano. Já tava suano as mão, co coração saltando e tal, aí eu me meti e disse: dêxa de sê besta! Tu aí podeno voá e eu que nem de ônibus consigo me deslocá. Aproveita!

TEFA - Tu quer ir no meu lugar?

TERNURINHA - Bá, eu quero. Tu dêxa?

TEFA - Sim, mas só até o momento do avião pousar.

TERNURINHA - E eu fui. Fiquei bem quieta no meu canto, sem fala co ninguém...Bá, ganhei até bala de goma, suco de laranja, batata frita...quando que me oferecem coisa boa assim na vida, né? Vi as nuvi lá de cima, oiáva pra báxo e via tudo pequeno...parecia de maquete. E eu nem sentia nada...das veiz parecia só que tava numa estrada de pedregúio, meio que tremilicava...mah foi bem tranquilo. Aproveitei pra mijá 5 veiz, porque é difíci conseguí banhêro do nada, né? Quase nunca tem banhêro público, e quando tem fecha antes das 10 hora da noite e só abre depois das 6 da manhã. $O$ corredor era de carpete...sei lá quantos ano eu não pisava num carpete. Carpete até parece palavra em francêis de tão chique. Assisti tevê, um monte de canal de tudo que é coisa que tu pode imaginá, de desenho até de comida. Bá, foi muito legal.

A Tefa tá acostumada com tudo isso, pode dexá escapá essas oportunidade, né... Ela pisa em carpete quando que qué, assiste tudo, come de tudo, mija em vaso a hora que qué. Eu não, eu tenho que aproveitá quando que essas coisa aparece, né.

E assim, Ternurinha e eu começamos a andar juntas, de braços dados e em constante diálogo, uma ajudando a outra. Ainda no ano de 2016, durante a disciplina Imagens Políticas na Cena: o Amor, ministrada pela Dra. Fátima de Costa Lima no Programa de Pós-Graduação em Teatro da UDESC, foi solicitado que, como trabalho final do semestre, escrevêssemos um artigo ou que criássemos alguma performance articulando nossas 
pesquisas a autores trabalhados ao longo do curso. Como minha pesquisa já estava se encaminhando para a relação que estabeleci entre Ternurinha e eu...

TERNURINHA - Esqueceu de dizê que a tua aula falava de CAPETAlismo, DEMOcracia, amor, necropolítica, mais um monte de coisa...

TEFA - Bem lembrado!

TERNURINHA - E que tu ainda tava te recuperano das locurage e até metade do curso tu fazia as aula pela internete.

TEFA - Verdade, só nos últimos 3 meses consegui comparecer presencialmente. Tá, continuando...

...decidi escrever meu artigo junto com Ternurinha, abordando os conceitos de Necropolítica, Capitalismo, Democracia e Amor. Conforme fomos elaborando o roteiro para a escrita, percebi que Ternurinha interagia a partir de imagens:

TEFA - Ternurinha, o que tu pensa sobre o capitalismo?

TERNURINHA - Coisa boa não é, se não o nome não começava com CAPETA... CAPETAlismo.

TEFA - E democracia?

TERNURINHA - Democracia é um sistema bem pelego que ajuda o CAPETAlismo se mantê.

TEFA- Como assim?

TERNURINHA - Tá, vâmo fazê de conta que democracia qué dizê que todo mundo tem espaço, é uma coisa que é pra todo mundo. Aí vem o CAPETAlismo e começa a botá valor nesse espaço. Quem tem mais dinhêro compra mais espaço, quem tem menos dinheiro, menos espaço. Quem não tem nada, que nem eu, se fode. O nome dela também mostra que ela não presta: DEMOcracia. Junta CAPETAlismo com DEMOcracia só pode dá coisa do capiroto. ${ }^{3}$

Surge a ideia, então, de organizar uma palestra com Ternurinha sobre o assunto. Eu traria os conceitos e a discussão, e ela as imagens, construídas a partir de suas vivências nas ruas, para mostrar como estes conceitos operam na prática.

TERNURINHA - Mah eu botei uma condição: que as coisa que eu ia lê na hora eu que ía fazê. Eu não me entendo com as luz que bota na parede cheia de letra, de computador... aquilo que estropia os óio...

TEFA - Os slides...Parecia não fazer sentido colocar Ternurinha para operar um computador, ou construir seu material por plataformas como powerpoint.

TERNURINHA - É, os eslaide. Eu só aceitava fazê a parada se eu podia fazê as coisa do meu jeito, de bricolage, que nem que eu aprendo nos albergue quando que eu vô, fazendo tudo co as coisa que cato por aí.

Foi quando comecei a pensar na viabilidade de aliar meus resíduos metafóricos (defeitos) aos meus resíduos concretos (materiais), e ver na minha produção de descartes possibilidades para criação cênica e poética.

TERNURINHA - Isso aí deu um crepe na cabeça dela...na nossa...porque começamo a pensá no lixo: o que que é lixo? Porquê que as coisa são lixo pra ela e pra mim não? Quando que as coisa vira inútil?

${ }^{3}$ Com base nas ideias do filósofo francês Alain Badiou no livro Elogio do Amor (2012), em que o autor discute a permissividade da democracia frente ao capitalismo, e questiona se 0 amor é possivel de acontecer nesta relação de mensurabilidade. 
A antropóloga britânica Mary Douglas (in memorian) no livro Pureza e Perigo: ensaio sobre a noção de poluição e tabu (1966) ao falar sobre os rituais como ações conectivas ao sagrado, reflete sobre o processo de escolha de materiais, substâncias, vestes, aparatos e símbolos selecionados para que eles aconteçam. Ao atribuirmos significado a certos elementos, acabamos por descartar outros... Descartamos justamente aquilo que não pertence à ordem que criamos. Pensando em nossas ordens diárias e ritos cotidianos, seria como se guardássemos a escova-de-dentes dentro da geladeira, a panela no banheiro, e o sutiã na poltrona da sala. O que está fora da ordem/sagrado é o que traz a ideia de impureza...e a impureza nos afasta da ordem/ sagrado. Segundo a autora:

Quando tivermos abstraído a patogenia e a higiene das nossas ideias sobre a impureza, ficaremos com a velha definição nas mãos: qualquer coisa que não está no seu lugar. Este ponto de vista é muito fecundo. Implica, por um lado, a existência de um conjunto de relações ordenadas e, por outro, a subversão desta ordem. A impureza nunca é um fenómeno único, isolado: Onde houver impureza, há sistema. Ela é o subproduto de uma organização e de uma classificação da matéria, na medida em que ordenar pressupõe repelir os elementos não apropriados. (Douglas, 1966. P.30.)

Seguindo a perspectiva de Douglas, sobre considerar como lixo aquilo que está fora do lugar, talvez possamos entender as reivindicações de Ternurinha no início deste artigo, quando a questionei sobre "sua sujeira espalhada pelo chão". Ternurinha atribuiu significados a objetos que antes, alguém, em algum momento, já não conseguiu mais enxergar. Aquilo que já não pertencia mais à ordem para alguém, nem mesmo para mim, Ternurinha tornou para si. O jogo do "sacralizar" e "dessacralizar"... de perceber que um mesmo objeto pode ser sagrado para alguém e não para outrem é o que me interessa aqui. (Talvez um dos princípios da outridade seja este?)

A vida contemporânea, pensada pela lógica do capitalismo tardio, em que o excesso de ofertas de serviços, produtos e relações opera, e que consequentemente a procura pelo consumo e pela ansiedade da satisfação aumenta, acaba gerando também de forma desmedida grandes quantidades de descartes ${ }^{4}$. Pessoas em situações semelhantes às de Ternurinha, desprovidas de condições econômicas e pertencentes a camadas sociais sem acesso a este tipo de sistema, acabam por encontrar nestes descartes possibilidades de sobrevivência, seja nos restos de comidas, de vestimentas, ou em objetos cujos significados são reinventados - como a caixa de papelão que no primeiro momento servia para embalar a televisão, e que depois foi transformado em isolante térmico por Ternurinha para que pudesse abrigar-se do frio.

Para que o material seja sagrado exige que alguém o sacralize, para o descarte é necessário alguém cuja a função seja descartar. No livro Historia de la Mierda (1978) o psicanalista francês Dominique Laporte fala sobre a relação entre a sociedade europeia medieval e sua merda. Segundo o autor, a limpeza só existe porque alguém exerce a função de descartador, concreta ou metaforicamente: seja o professor que descarta os excessos do idioma lapidando-o junto do aluno; seja o gari que retira

${ }^{4}$ Relacionando os conceitos de consumo e hiperconsumo do filósofo francês Gilles Lipovetsky em A Felicidade Paradoxal (2007) e o conceito de liquidez ao longo de várias obras de Zigmunt Bauman, mas que aqui trago especificamente Capitalismo Parasitário e Outros Temas Contemporâneos (2010). 
das ruas o excesso de sujeira e deposita nas lixeiras; seja a pessoa que defeca e retira de si o excesso do que o corpo não aproveitou. Por mais que o corpo em questão (neste caso lixeira ou corpo humano) fique limpo, para onde vai o descarte? As lixeiras precisam ser esvaziadas, a merda precisa escoar para algum lugar. O lixo não some, não termina...ele apenas se transforma. Segundo o autor, podemos ver no descarte um potencial criador, processador: "Todo está en todo, cada cosa contiene su principio y su contrario; lo que quema y abrasa, con el tempo fecunda y nutre, el olor a estadizo se transforma en perfume y la podredume se convierte en oro" (Laporte, 1989, p.40).

Ternurinha é construída por mim como um grande excesso meu, sem exímias lapidações. Ela se empresta para vestir meus descartes e os expõe a mim mesma. Aquilo que considero anômalo ou fora de lugar em mim, é o que dá vida à Ternurinha. Ternurinha é meu rechaço, meu lixo.

TERNURINHA - Oh, desgraçada! Eu tô quieta mah tô aqui. Eu sô teu lixo? Desde quando que sô teu lixo? Te enxerga!

TEFA - Calma! Estou dizendo que tu és a forma de valorizar meu lixo, minha maneira de colocar-me em resistência a um sistema cuja lógica é patriarcal, que insiste na objetivação e acertividade das relações, que não abre possibilidade de questionamentos e dúvidas sobre qualquer decisão, e que através da arbitrariedade tenta manter-se inabalável em sua estrutura. Tu não pertences a este modelo de organização social...aliás, este modelo não quer que tu participes dele...Mas tu te utilizas disso para denunciar e subverter a ordem, para mostrar que esta ordem é cheia de contradições e por isso pode ser contestada.

TERNURINHA - Hum...Primero chama de lixo, depois qué me adulá....

TEFA - Mas o lixo não necessariamente é ruim...Lembra do que falei antes, citando o Laporte, sobre o potencial transformador do lixo? Depende do ângulo que eu olho, eu posso valorizar tudo...até o lixo. Eu te valorizo demais, Ternurinha.

(Ternurinha pensa por alguns instantes em silêncio. Pega o livro de Mary Douglas e folheia-o. Encontra uma de minhas anotações, e com muita calma e dificuldade tenta ler.)

TERNURINHA - Aaaa..... de.....................ssss........sooooooor.........dem......... ееееее.....éééée.....p...ppро......is......po.is......aаaаaоoо....mmmmmm... еeеe.... me...........m...o....mo.....meessmmooo... te.......m..........po, ssssssímmmmmm.....b...o...bo......lllllloooooo.... de.... pe.......ri......ccсco..... gооооо....pe..ri...go...... e... de......poooooo......der. ${ }^{5}$

TEFA- Está indo bem, Ternurinha!!! Entendeste o que acabaste de ler? TERNURINHA - Não.

TEFA-A Mary Douglas está dizendo que a desordem é perigosa porque significa poder. Por exemplo, quando muitas possibilidades são apresentadas de maneira em principio desordenada, ao mesmo tempo em que pode parecer aberta para leituras, ela oferece material para que alguma ordem se imponha.

TERNURINHA - Tipo eu... quando apareço como um monte de lixos amontoado, sem orde pra ti...tu óia pra mim e consegue arrumá de vários jeito...criá otros sistema...otras orde.....

TEFA - Isso. As tuas palestras, por exemplo. (Pausa). Tu comentaste para o pessoal sobre tuas palestras?

TERNURINHA - Não...eu tava cansada e tu não parô de fala. Tá, pessoal, eu sô palestrante. A TEFA me explica os assunto, os livro, os letrado que falo das coisa,

5 "A desordem é, pois, ao mesmo tempo, símbolo de perigo e de poder". (Douglas, 1966. p.72) 
eu faço meu eslaide ${ }^{6}$ do meu jeito de bricolage...que é uma coisa que a gente reaproveita coisa véia e quebrada pra fazê otras....e vô pra escola de criança.... de adulto.....de dotoramento....igreja....praça....bah...eu vô pra todo lugá que me convido pra palestrá7. E falo, né. Tem gente que me óia e nem acredita que eu palestro. Fico com umas cara de "bah, desde quando uma desgraçada dessas palestra?". Mah eu palestro mesmo, de tudo, tudo. Se quisé me chama eu sô bem barata, é só um pastel e um refri.

TEFA - Isso mesmo, Ternurinha. Enxergo a ti e às tuas palestras como ferramentas para recriar a minha visão de aprendizado, de educação, de construção de conhecimento, de fazer teatro. Porém, há um cuidado que preciso ter para não estigmatizar, cristalizar ou sacraliza-las a ponto de não conseguir me desfazer de vocês...Ou da maneira como vocês existem hoje. Entende?

TERNURINHA - Mas e daí se as coisa não mudo?

TEFA - Se não muda não evolui.

TERNURINHA - Mah pra mudá e evoluí precisa fazê mais lixo.

TEFA- (Penso....) Sim...ou não. Se eu pegar o lixo e só mudar a ordem dele...não gera mais lixo, mas pode aparecer outra leitura, mesmo sendo utilizado o mesmo material. Quando tu pega o papelão da televisão para construir teus slides é isso que tu fazes, não?

TERNURINHA - Mas cada papelão tem só 2 lado...depois que usei os dois eu também boto fora.

TEFA - ...

TERNURINHA - Não adianta, tu não vai resolvê os problema todo. Tu só consegue í até aqui...Tô só te mostrando que até pra criá ideia tu ta descartando otras. Não tem problema se tu fazê lixo...Problema é quando tu não aceita que ele saíro de ti. Acho que se todo mundo aceitava que faz as merda e olhasse pra elas com calma, ninguém ía cobrá tanto das merda do otro...

Acho que ía tê menos gente excluída, porque se o CAPETAlismo vai afunilando as coisa, que só quem parece o mais perto de perfeito (tô falando do "perfeito" que o CAPETAlismo inventa) que chega no topo e é vencedor, os que não chego são fracassado... não presto...não servem pra nada...tão fora do lugar, né?...Oh, esse aqui é um dos eslaide que eu fiz pra palestra que eu dô que chama DEMOcracia e CAPETAlismo.

\section{${ }^{6}$ Slides.}

${ }^{7}$ Segue o link da teatropalestra Nem Uma a Menos https://www.youtube.com/watch?v=_aGQGReEBdU, gravado no dia 24 de agosto de 2017, durante o Ciclo de Teatros Feministas, organizado pelo Programa de Pós-Graduação em Teatro da UDESC, junto do Grupo de Estudos Egrégora Feminista. Acesso em: 17 set. 2018. 


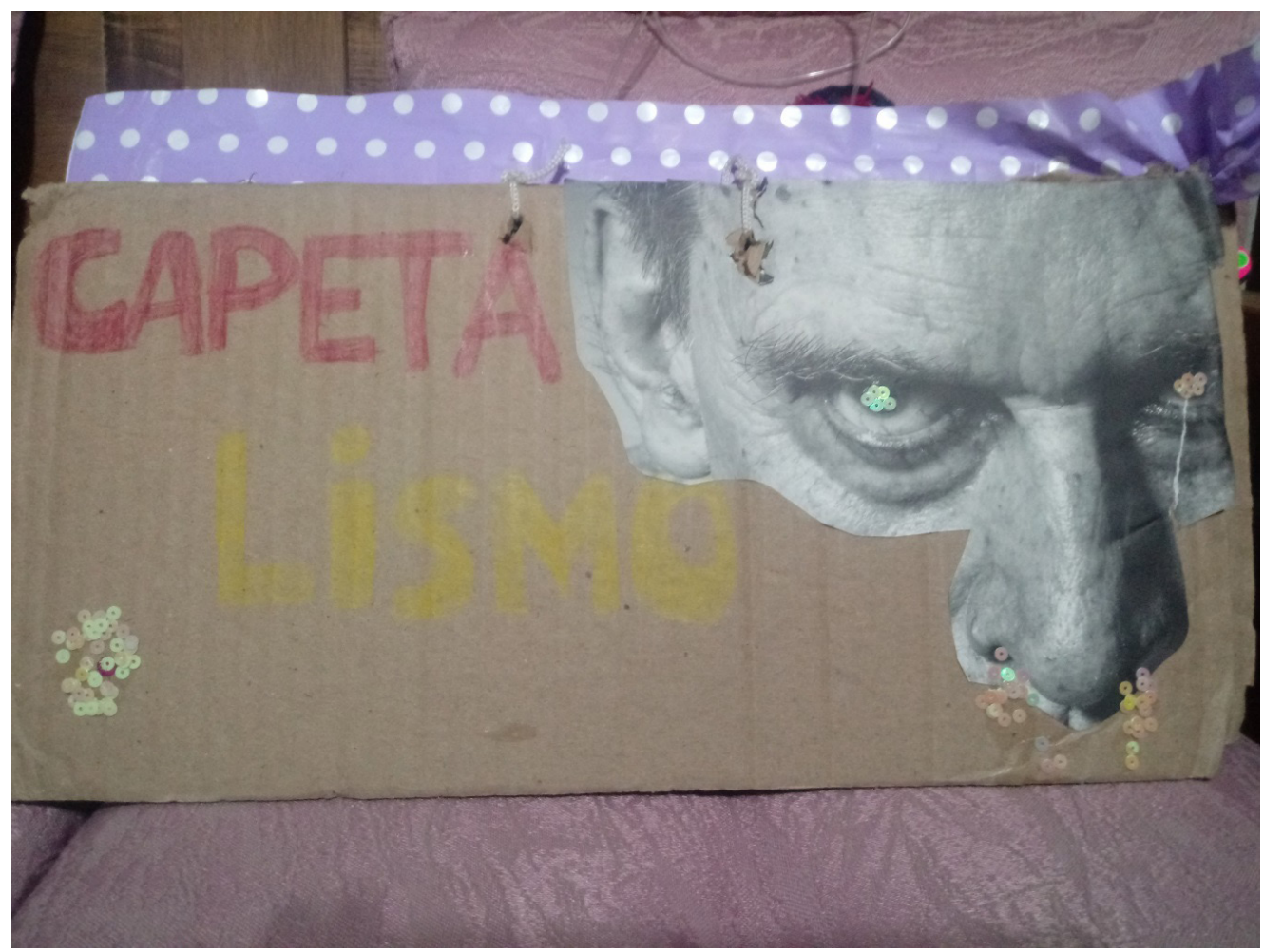

Figura 3 - Slide da palestra DEMOcracia e CAPETAlismo.

Florianópolis/SC-2018.

Crédito de Tefa Polidoro.

O CAPETAlismo fica oiando pra gente co esse zóio esbugalhado de brilho e vampirismo, te chamando pra ajudá ele a vivê. Quem não consegue ajudá ou não qué ajudá, ele invisibiliza e descarta. Se eu tô fora do lugar...se ele não qué me dexá fazê parte dele, eu tenho que cria um espaço onde que eu posso vivê, porque se não eu e os outro que são que nem eu acabo de existí...que nem os hipopótamo. TEFA - Entendi. Então tu cria contexto para valorizar o que algo ou alguém em outro contexto não tem valor? Cria lugar para o que aparentemente, sob outra ordem, está fora de lugar?

TERNURINHA - Meio rocambolesco o que tu falô, mas acho que é por aí.

Criamos, então, sob esta lógica, a teatropalestra intitulada DEMOcracia e CAPETALISMO como trabalho final para a disciplina Imagens Políticas na Cena: o Amor, apresentada em dezembro de 2016 no Centro de Artes da UDESC. ${ }^{8}$ Ao final daquele mesmo ano, a professora Dra. Fátima Costa de Lima foi convidada para fazer uma fala resumida sobre o conteúdo abordado na disciplina durante a Mostra Independente XOQUE - Performances e Arte, que aconteceria dia 30 de novembro de 2016, um domingo à tarde, no Velho Terminal Rodoviário, no centro de Florianópolis. Ela convidou Ternurinha e eu para participarmos com nossa teatropalestra.

${ }^{8}$ Pode ser acessada pelo link https://www.youtube.com/watch?v=2nJh4oEuFI0\&index=6\&list=UUtchN5z1wbSw4m78LqHMOfQ. Acessado em 17 de outubro de 2018. 


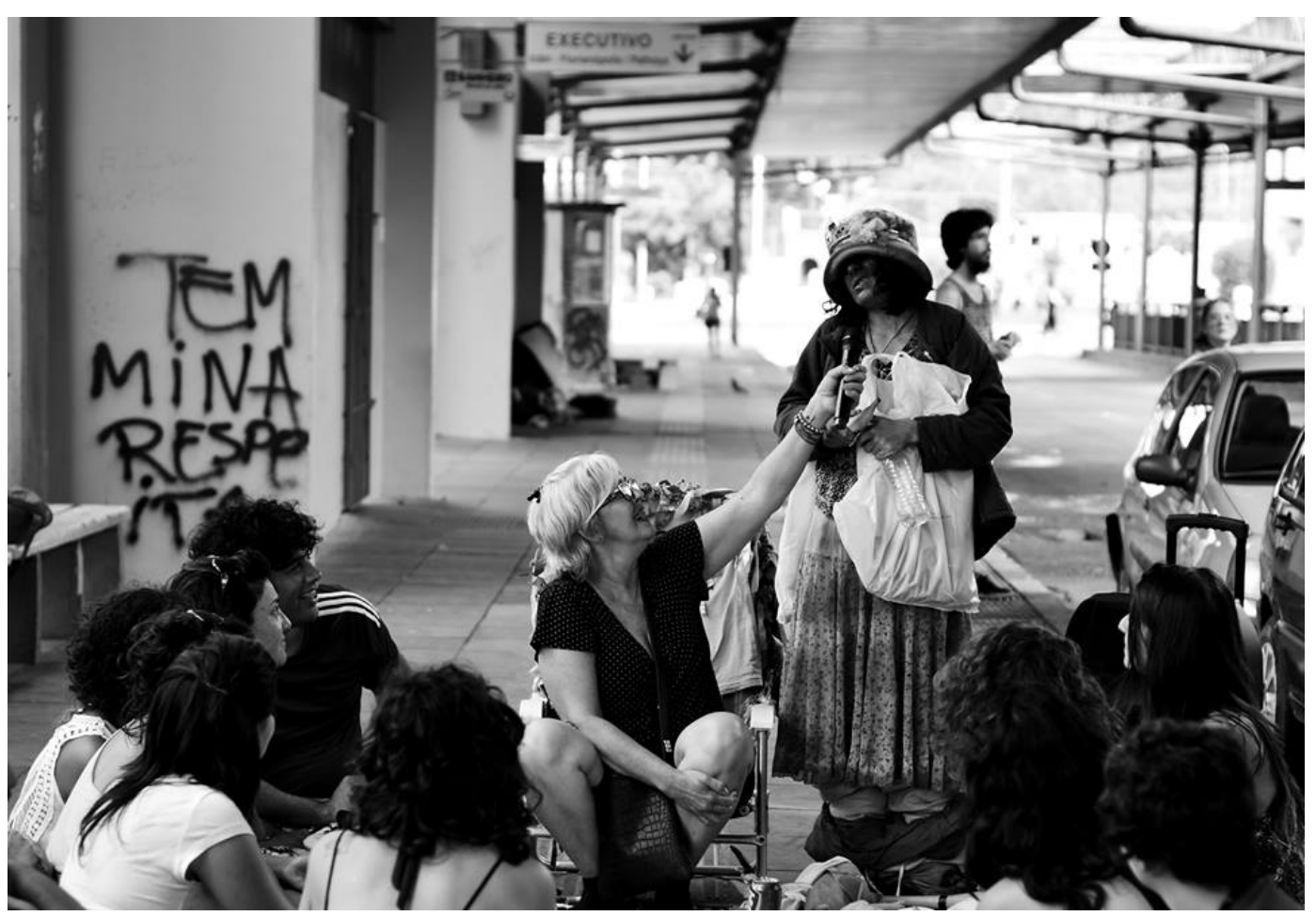

Figura 4 - Profa. Dra. Fátima e Ternurinha durante a teatropalestra DEMOcracia e CAPETAlismo Florianópolis/SC- 2016.

Créditos: Organização da Mostra Independente XOQUE

Com esta experiência passei a enxergar a teatropalestra como um caminho possível para abordar questões que me competem relacionadas a teorias políticas e sociais a partir do teatro. Depois da teatropalestra DEMOcracia e CAPETAlismo, criamos como finalização da disciplina Introdução aos Estudos de Teatros Feministas, ministrada pela professora Dra. Maria Brígida de Miranda, também no Programa de Pós-Graduação em Teatro da UDESC, no ano de 2017, a teatropalestra Nem Uma a Menos. ${ }^{9}$

TERNURINHA - Nessa a gente pergunta se todas muié são considerada "uma" na sociedade. Que tá certa a frase "nem Uma a Meno", que é o mínimo que a gente qué...mah de que "uma" a gente tá falano quando que diz isso? Porque muié que nem eu morre todos dia, em todos canto do mundo, e ninguém fica sabenu.

Já apresentamos esta teatropalestra em escolas municipais e estaduais, universidades públicas e privadas, igrejas, ruas e sindicatos da região sul do Brasil, além de participar de festivais de teatro como VII Festival Esse Monte de Mulher Palhaça, acontecido no Rio de Janeiro entre os dias 27 e 30 de setembro de 2018, e a II Mostra Rosa Teatral, realizada pelo Programa de Extensão Mulheres em Cena/PPGT/UDESC, durante o mês de outubro de 2018.

${ }^{9}$ Pode ser acessada pelo link https://www.youtube.com/watch?v=_aGQGReEBdU\&list=UUtchN5z1wbSw4m78LqHMOfQ\&index=8. Acessado em 17 de outubro de 2018. 


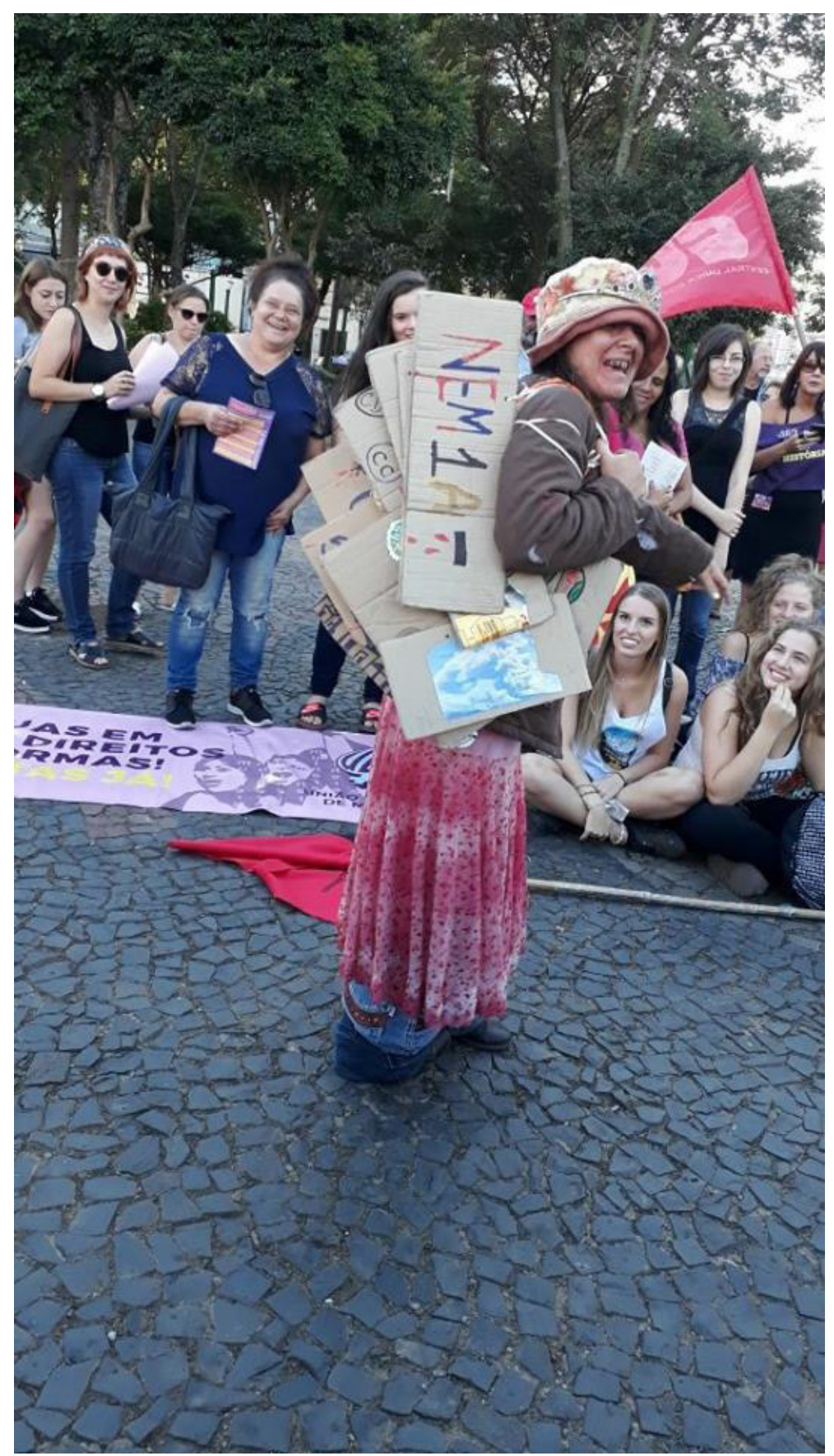

Figura 5 - Atriz Tefa Polidoro como Ternurinha 08 de Março - Dia Mundial das Mulheres parceria com o Fórum da Mulher Caxiense Caxias do Sul/RS- 2018. Crédito de Vitória Nervo 


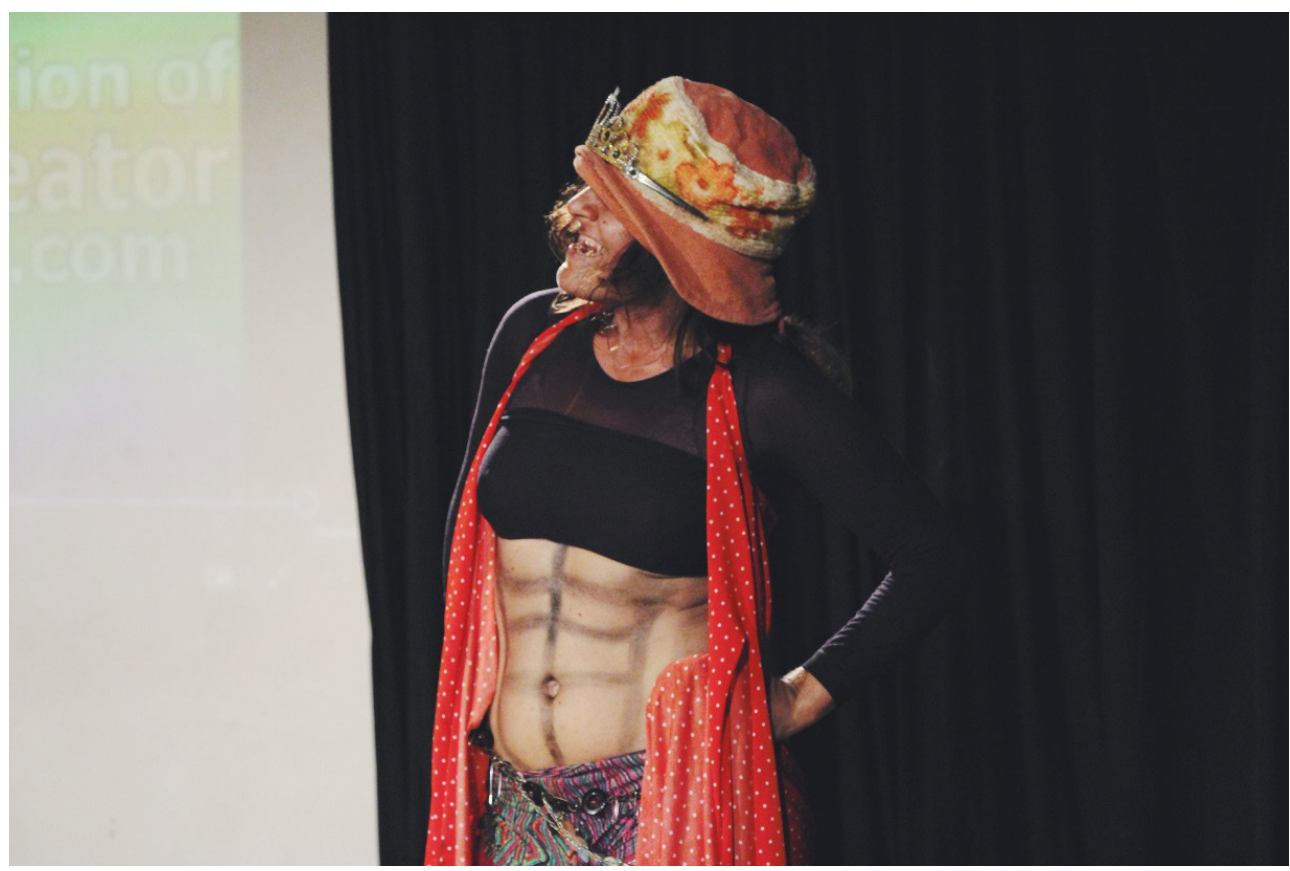

Figura 06 - Atriz Tefa Polidoro como Ternurinha

I Ciclo Teatros feministas em Cena - realizada pelo PPGT/ UDESC

Florianópolis/SC - 2017. Crédito de Mariana Rotilli

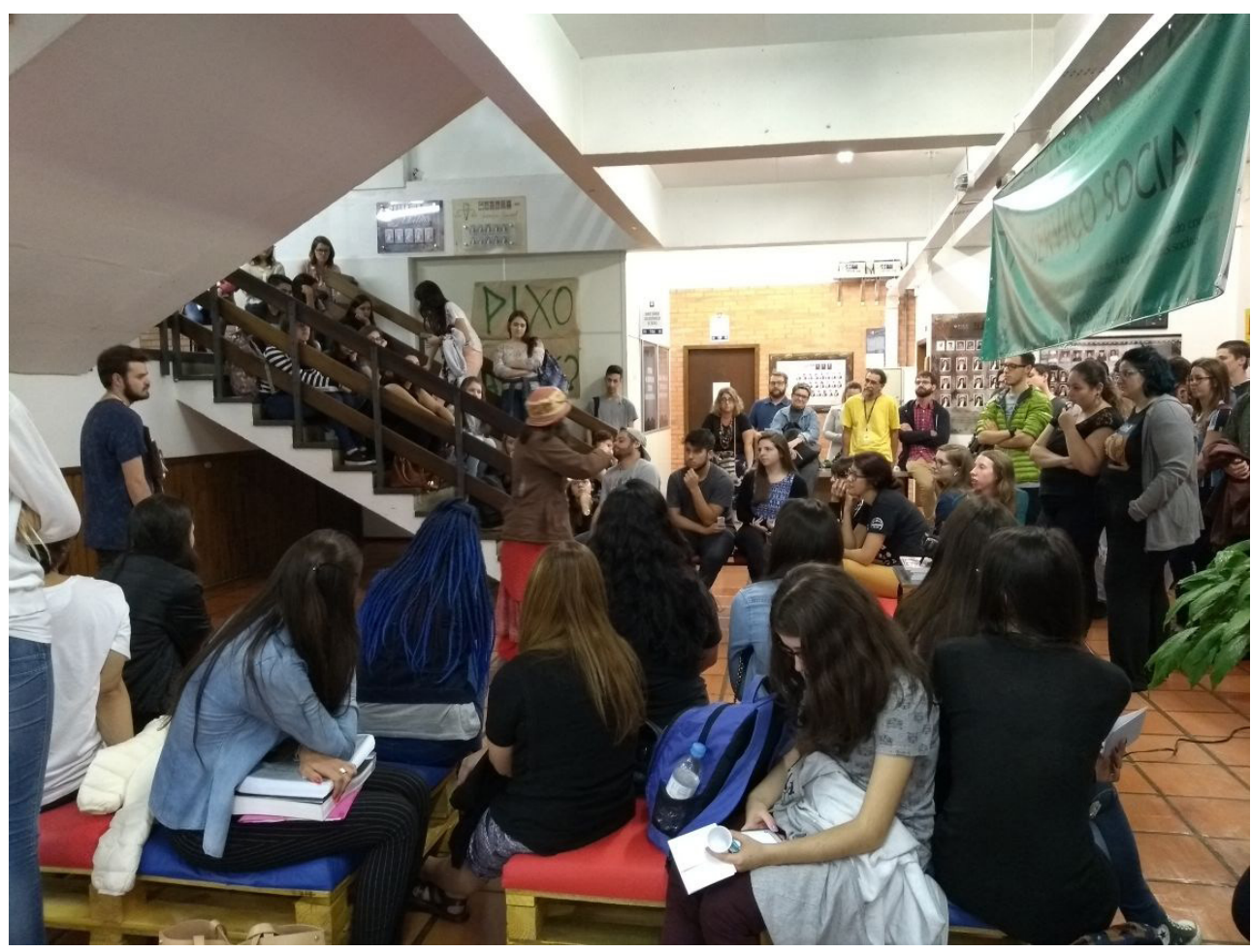

Figura 07 - Atriz Tefa Polidoro como Ternurinha

Curso de História da Universidade de Caxias do Sul

Caxias do Sul/RS - 2018. Crédito de Ramon Tisott

E o que antes parecia estar fora de lugar, começa a encontrar lugar para encaixes.

Percebi nas teatropalestras possibilidades de levar discussões referentes a "feminismos", "capitalismo" e "democracia" a qualquer espaço, primeiramente por conta de sua prática mobilidade... 
TERNURINHA - Porque nóis precisamos só levá uma mala cos eslaide e com minhas rôpa...Isso dá pra fazê até de apé, de ônibus, de carro, de jegue porque não é muita coisa...

...Seguida por seu custo financeiro quase nulo...

TERNURINHA - Porque é tudo lixo dela e dos outro que eu pego e faço virá em coisa boua...eu aproveito tudo.

...Finalizando pela capacidade de dialogar conceitos com experiências da vida de Ternurinha, numa tentativa de levar a ciência para vários espaços, e também as ruas para o ambiente acadêmico, buscando a construção de conhecimento por uma via horizontal em que práxis e teoria sejam...ou estejam...em unidade.

\section{Referências}

BADIOU, Alain. Elogio do Amor. Bueno Aires: Ed. Paidós, 2012.

BAUMAN, Zygmunt. O mal-estar da pós-modernidade. Rio de Janeiro: Jorge Zahar Editor, 1998.

Vida para consumo - A transformação das pessoas em mercadorias. Rio de Janeiro: Jorge Zahar Editor, 2008.

Capitalismo parasitário. Rio de Janeiro: Jorge Zahar Editor, 2010.

CABRAL, Muniz Sodré A.; SOARES, Raquel Paiva de A. O Império do Grotesco. Rio de Janeiro: Mauad, 2002.

DOUGLAS, Mary. Pureza e Perigo: ensaio sobre a noção de poluição e tabu; tradução Sonia Pereira da Silva. Lisboa: Edições 70 Ltda, 1966.

LIPOVETSKY, Gilles. A felicidade paradoxal: ensaio sobre a sociedade do hiperconsumo; tradução Maria Lúcia Machado. São Paulo: Companhia das Letras, 2007.

RAGO, Luzia Margareth. A aventura de contar-se: feminismos, escrita de si e invenções da subjetividade. Campinas: São Paulo: Editora da Unicamp, 2013.

RAZNOVICH, Diana. Manifesto 2000 of Feminist Humor, In.:Women and performance: a jornal of feminist theory. Nova York: Univrsidade de Nova York, 2000.

RIAL, Carmen. O poder do lixo: abordagens antropológicas dos resíduos sólidos. Rio de Janeiro: Associação Brasileira de Antropologia, 2016.

RUSSO, Mary. O grotesco feminino: risco, excesso e modernidade. Trad. Talita M. Rodrigues. Rio de Janeiro: Rocco, 2000. 
SCANLAN, John. On garbage. London: Reaktion Books, 2005.

STRAUSS, Lévi. O pensamento selvagem. Tradução: Tânia Pellegrini. Campinas: São Paulo: Papirus, 1989.

Recebido em: 25/09/2018 Aprovado em: 20/10/2018 